\title{
Comparison of fluorescent single-strand conformation polymorphism analysis and denaturing high-performance liquid chromatography for detection of EXT1 and EXT2 mutations in hereditary multiple exostoses
}

\author{
Carol Dobson-Stone ${ }^{1}$, Roger D Cox ${ }^{2}$, Lorne Lonie ${ }^{1}$, Lorraine Southam², Maria Fraser ${ }^{3}$, \\ Carol Wise ${ }^{4}$, François Bernier ${ }^{5}$, Shirley Hodgson ${ }^{6}$, Daniel E Porter ${ }^{3}$, \\ A Hamish RW Simpson ${ }^{3}$ and Anthony P Monaco ${ }^{1}$
}

\begin{abstract}
${ }^{1}$ The Wellcome Trust Centre for Human Genetics, and ${ }^{3} \mathrm{~N}$ uffield Department of Orthopaedic Surgery, University of Oxford, Oxford, UK; ${ }^{2}$ Medical Research Council, Mammalian Genetics Unit, Harwell, UK; ${ }^{4}$ Scottish Rite Hospital for Children, Dallas, Texas, USA; ${ }^{5}$ Alberta Children's Hospital, Alberta, Canada; ${ }^{6}$ Division of Medical and Molecular Genetics, Guy's Hospital, London, UK
\end{abstract}

EXT1 and EXT2 are two genes responsible for the majority of cases of hereditary multiple exostoses (HME), a dominantly inherited bone disorder. In order to develop an efficient screening strategy for mutations in these genes, we performed two independent blind screens of EXT1 and EXT2 in 34 unrelated patients with HME, using denaturing high-performance liquid chromatography (DHPLC) and fluorescent single-strand conformation polymorphism analysis (F-SSCP). The mutation likely to cause HME was found in $29(85 \%)$ of the 34 probands: in 22 of these $(76 \%)$, the mutation was in EXT1; seven patients (24\%) had EXT2 mutations. Nineteen of these disease mutations have not been previously reported. Of the 42 different amplicon variants identified in total in the cohort, 40 were detected by DHPLC and 39 by F-SSCP. This corresponds to mutation detection efficiencies of $95 \%$ and $93 \%$ respectively. We have also found that we can confidently distinguish between different sequence variants in the same fragment using F-SSCP but not DHPLC. In light of this, and the similarly high sensitivities of the two techniques, we propose to continue screening with F-SSCP. European Journal of Human Genetics (2000) 8, 24-32.

Keywords: single-strand conformation polymorphism analysis; denaturing high-performance liquid chromatography; mutation detection; SNP detection; hereditary multiple exostoses; diaphyseal aclasis; EXT1; EXT2

Introduction

Single-strand conformation polymorphism analysis (SSCP) and denaturing high-performance liquid chromatography (DHPLC) are both techniques that can detect point mutations in a DNA fragment of interest. ${ }^{1,2}$ They are com-

Correspondence: Anthony P Monaco, Wellcome Trust Centre For Human Genetics, Roosevelt Drive, Headington, Oxford OX3 7BN, UK. Tel: +44 1865 287503; Fax: +44 1865 287501; E-mail: anthony.monaco@well.ox.ac.uk

Received 6 August 1999; revised 15 September 1999; accepted 22 September 1999 plementary methods, in that SSCP detects base changes in single-stranded DNA (sSDNA), whereas DHPLC utilises double-stranded DNA (dsDNA). The basic techniques have been well established, but the application of four-colour fluorescence technology to visualise products on SSCP gels ${ }^{3}$ and the incorporation of DHPLC into an integrated mutation detection system such as the Transgenomic WAVE ${ }^{\mathrm{TM}}$ DNA Fragment Analysis System ${ }^{4}$ are both recent adaptations. These modifications have various advantages in terms of ease of application, increased throughput and, most importantly, point mutation detection efficiency. 
In fluorescent SSCP (F-SSCP), DNA is denatured then run under non-denaturing conditions: the separated strands are therefore free to adopt three-dimensional conformations dependent on their sequence. A single base-pair alteration can therefore cause a conformational change that will alter the electrophoretic mobility of the molecule when run on a non-denaturing polyacrylamide gel. If the DNA fragment is fluorescently labelled on both strands, sufficient variation in mobility relative to a wild-type DNA control can be detected on a fluorescent image analyser, interpreted as a sequence change and analysed accordingly.

In DHPLC, if a DNA fragment heterozygous for a sequence change is heat-denatured then slowly cooled, a mixture of homo- and heteroduplexes is formed. The heteroduplexes, due to mismatch pairing, will form weaker interactions with a hydrophobic column matrix when partially denatured and will therefore be eluted sooner than homoduplexes during reverse-phase ion-exchange HPLC. DNA fragments containing heterozygous base changes can therefore be identified by elution peak pattern variations relative to those from homozygous control DNA.

Hereditary multiple exostoses (HME, MIM no. 133700) is an autosomal, dominantly inherited disorder characterised by the presence of multiple, cartilage-capped osteochondromas (exostoses) that develop mainly from the juxtaepiphyseal regions of the long bones. The exostoses develop during childhood and grow until closure of the growth plate at puberty. ${ }^{5,6,7}$ It is the most frequent of all skeletal dysplasias, with an estimated prevalence of $1 / 50000$ in the population. ${ }^{8}$ Complications include: pressure on neighbouring nerves or blood vessels; skeletal deformity and short stature; limb length inequalities; and difficulty in joint movement and arthritis. Several operations may be required to remove the most severe growths. The gravest consequence of the disease is the possible transformation of a benign exostosis to a malignant osteo- or chondrosarcoma. The transformation rate of any single exostosis is very low, but the probability of an individual developing a malignant tumour is higher and depends on the number of exostoses present. Malignant transformation is observed in $1-5 \%$ of HME patients. ${ }^{5,7,8}$

Three loci, on chromosomes 8q24.1 (EXT1), ${ }^{9}$ 11p11-p13 $(\text { EXT2) })^{10,11}$ and 19p (EXT3) $)^{12}$ were identified through linkage studies as being involved in the development of HME. EXT3 has not yet been cloned, but EXT1 and EXT2 werecloned and sequenced in 1995 and 1996 respectively. ${ }^{13-15}$ Loss of heterozygosity found on chromosomes 8 and 11 in chondrosarcomas $^{16,17}$ and the increased relative risk conferred by HME of chondrosarcoma development indicate that EXT1 and EXT2 act as tumour suppressor genes. Two recent studies ${ }^{18,19}$ have implicated the EXT genes in synthesis and display of cell surface heparan sulphate glycosaminoglycans (GAGs). GAGs are believed to act as cofactors of several signalling pathways affecting cell growth and differentiation, ${ }^{20}$ consistent with a possible role in tumour growth.
Several mutations in EXT1 and EXT2 responsible for the HME phenotype have been published: ${ }^{14,21-24}$ most of these are loss-of-function mutations, supporting the postulated tumour suppressor function of these gene products. Additional mutation screening of EXT1 and EXT2 could enable further elucidation of the function of these genes, and will facilitate a possible correlation of phenotype with gen otype.

Both F-SSCP and DHPLC have been claimed to enable rapid, robust scanning of unknown mutations with high detection rates. We decided to perform a direct comparison between the two technologies in order to ascertain the better mutation screening strategy for the EXT1 and EXT2 genes; and to establish the strengths and weaknesses of each technique to enable their effective utilisation in future applications.

\section{Materials and methods Patients}

Thirty-four probands were selected from unrelated families with clinical symptoms of HME. Criteria for inclusion in the study were three or more radiographically confirmed osteochondromas. Twenty-eight families were referred from the Nuffiel d Orthopaedic Centre, Oxford, UK. DNA samples from HME families were also provided from: the Scottish Rite Hospital for Children, Texas, USA (four families); Alberta Children's Hospital, Alberta, Canada (one family) and Guy's Hospital, London, UK (one family).

\section{DNA extraction}

Genomic DNA was extracted either from blood, using the Nucleon DNA extraction kit (Scotlab, Lanarkshire, UK), or from buccal swabs, by use of the protocol described previously. $^{21}$

\section{Study layout}

In order to conduct the study as an objective comparison, genomic DNA was aliquoted into duplicate tubes and one set each given to two operators, one using F-SSCP and one using DHPLC for sequence variant detection. Each operator worked independently and neither had any prior knowledge about the nature or presence of mutations in the proband DNA.

\section{PCR amplification of exons}

For the proband of each family, EXT1 and EXT2 exons with flanking intronic regions were PCR amplified by use of specific primer pairs (Table1). For F-SSCP, EXT1 primer pairs were ordered with 5' HEX, 6-FAM or TET fluorescent dye labels; HEX, 6-FAM or NED dyes (offering better spectral separation) were the labels on the F-SSCP EXT2 primers. The primer pairs for EXT2 exons 2-14 were designed from sequences available from Genbank (accession numbers U67356-U67368). F-SSCP cycling conditions were as follows: $94^{\circ} \mathrm{C}$ for $18 \mathrm{~min}$; $35 \mathrm{cycles}$ of $94^{\circ} \mathrm{C}$ for $30 \mathrm{~s}$, the annealing 
temperature (Table 1 ) for $30 \mathrm{~s}$, and $72^{\circ} \mathrm{C}$ for $30 \mathrm{~s} ; 72^{\circ} \mathrm{C}$ for $5 \mathrm{~min}$. PCR reactions were carried out on a PTC 225 Thermal Cycler (MJ Research Inc., Massachusetts, USA) using AmpliTaq Gold ${ }^{T M}$ DNA polymerase (PE-Applied Biosystems, Cheshire, UK). DHPLC cycling conditions were as follows: $94^{\circ} \mathrm{C}$ for $2 \mathrm{~min}$; a touchdown of $14 \mathrm{cycles}\left(94^{\circ} \mathrm{C}\right.$ for $1 \mathrm{~min} ; 7.5^{\circ} \mathrm{C}$ above the annealing temperature with $-0.5^{\circ} \mathrm{C}$ per cycle for $1 \mathrm{~min}$; $72^{\circ} \mathrm{C}$ for $1 \mathrm{~min}$ ); $25 \mathrm{cycles}$ of $94^{\circ} \mathrm{C}$ for $1 \mathrm{~min}$, the annealing temperature for $1 \mathrm{~min}, 72^{\circ} \mathrm{C}$ for $1 \mathrm{~min} ; 72^{\circ} \mathrm{C}$ for $5 \mathrm{~min}$. PCR amplification was carried out using the Expand ${ }^{\mathrm{TM}}$ High Fidelity PCR system (Boehringer Mannheim UK, Sussex, UK), on the thermal cycler detailed above.

\section{F-SSCP analysis}

The protocol outlined below was based on recommendations set out in the 'PCR SSCP Analysis' applications note supplied by PE-Applied Biosystems. Initially, each different DNA

Table 1 Primers used to amplify EXT1 and EXT2 exons ${ }^{a}$

\begin{tabular}{|c|c|c|c|}
\hline Gene, exon and primer & Primer sequence $\left(5^{\prime}\right.$ to $\left.3^{\prime}\right)$ & PCR product size (bp) & PCR conditions ${ }^{C}$ \\
\hline$\overline{\text { EXT1, exon } 1(1 \mathrm{~A}) \mathrm{F}^{\mathrm{b}}}$ & TGGGAAACTTGGGTGATTCTT & 164 & $a$ \\
\hline EXT1, exon 1 (1A) R & GGCTGTGGCTCCTCGATGC & & \\
\hline EXT1, exon 1 (1B) F & CTCAGCTGGCTCTTGTCTCG & 235 & $\mathrm{~b}$ \\
\hline EXT1, exon 1 (1B) R & GTTGGCATCTCGCTTCTGC & & \\
\hline EXT1, exon 1 (2) $\mathrm{F}$ & CCCTTCGTTCCTTGGGATC & 276 & $\mathrm{a}$ \\
\hline EXT1, exon 1 (2) R & GACAAAGAGGCACGCCTG & & \\
\hline EXT1, exon 1 (3) F & GTTACCAAAACATTCTAGCG & 268 & a \\
\hline EXT1, exon 1 (3) R & CTTTGGCCAGCATCGCCTGG & & \\
\hline EXT1, exon 1 (4) F & TTTATATTCCGGCACTTGGC & 242 & a \\
\hline EXT1, exon 1 (4) R & TCCCTGTCAGGTACCTCTTCC & & \\
\hline EXT1, exon 1 (5) F & TTCAACACCATCCCTCCTC & 246 & $\mathrm{a}$ \\
\hline EXT1, exon 1 (5) R & CAAGGCTGACTCCCAAAGAC & & \\
\hline EXT1, exon $11 \mathrm{~F}$ & GCACTTCTCTCATATTATCC & 289 & $\mathrm{C}$ \\
\hline EXT1, exon $11 \mathrm{R}$ & AAGAGAGAGCAGCTTGAC & & \\
\hline EXT2, exon 2 (1) F & GTCTTTTCAAGTGTCATTTGC & 235 & a \\
\hline EXT2, exon 2 (1) R & CCAAAACTGAAACATGCCAG & & \\
\hline EXT2, exon 2 (2) R & GAAGCCACAGCGATAGACAT & & \\
\hline EXT2, exon 2 (3) F & CAGCCGACAGTCCCATCCC & 258 & $\mathrm{~b}$ \\
\hline EXT2, exon 2 (3) $R$ & CGATGGAGGGAACAAACAGA & & \\
\hline EXT2, exon 2 (4) F & CTTTGGCGTCTCTGTCAGCA & 227 & $b$ \\
\hline EXT2, exon 2 (4) $R$ & CAAGTATCTCCTGGGGGCTG & & \\
\hline EXT2, exon $3 \mathrm{~F}$ & GACTCTTGTCTTTTCATAGTT & 192 & $\mathrm{~b}$ \\
\hline EXT2, exon $3 \mathrm{R}$ & ATCTTGAACCCATCATAAGG & & \\
\hline EXT2, exon $4 \mathrm{~F}$ & GTAATTCCTGTTCCTCTCCAC & 244 & $\mathrm{~b}$ \\
\hline EXT2, exon $4 \mathrm{R}$ & CACAGATTCAGTAAAGGCAC & & \\
\hline EXT2, exon $5 \mathrm{~F}$ & CTGCAATTTTCCAATCACCTG & 270 & $\mathrm{~b}$ \\
\hline EXT2, exon $5 \mathrm{R}$ & TCCTGAGCCTTTGCGAGAG & & \\
\hline EXT2, exon $6 \mathrm{~F}$ & CTAGTTTGTAATCTCTTGCCT & 220 & $\mathrm{~b}$ \\
\hline EXT2, exon $6 \mathrm{R}$ & CGCAGAACCACTAATGTAGA & & \\
\hline EXT2, exon $7 \mathrm{~F}$ & CTGTGAAGGGCTGTGTGTATG & 200 & $\mathrm{~b}$ \\
\hline EXT2, exon $7 \mathrm{R}$ & CCAGTCAAGGCCACCATTTC & & \\
\hline EXT2, exon $8 \mathrm{~F}$ & GTCTCGCTTGCTCACTTAAAA & 233 & $\mathrm{~b}$ \\
\hline EXT2, exon $8 \mathrm{R}$ & CTTCCACCCACCCTGACAG & & \\
\hline EXT2, exon $10 \mathrm{R}$ & TATTAAACATATAAACACACT & & \\
\hline EXT2, exon $11 \mathrm{~F}$ & TGGTTGCTGTCTGAATTGGGA & 242 & $\mathrm{e}$ \\
\hline EXT2, exon $11 \mathrm{R}$ & GTATCATTCTCTCAGTTTTGT & & \\
\hline EXT2, exon $12 \mathrm{~F}$ & TTATCAGCTAAAGGGAACTG & 227 & $\mathrm{~b}$ \\
\hline EXT2, exon $12 \mathrm{R}$ & CCCAAGATCACAAAGCAAGT & & \\
\hline EXT2, exon $13 \mathrm{~F}$ & AGCATGATTTTATTGTCCTTG & 198 & $\mathrm{~b}$ \\
\hline EXT2, exon $13 \mathrm{R}$ & GGCAGGAAATAGAGATCAGA & & \\
\hline EXT2, exon $14 \mathrm{~F}$ & СТCСТCCССACСТССТCTC & 215 & $f$ \\
\hline EXT2, exon $14 \mathrm{R}$ & CCCTCTGTCCCAGCCTCAC & & \\
\hline
\end{tabular}

asequences for EXT1 exons 2-10 are reported in the article by Wells et al ${ }^{23}$

${ }^{b}$ Due to the large size of EXT1 exon 1 and EXT2 exon 2, we used overlapping sets of primers to amplify these regions. Fragment numbers are indicated in parentheses.

${ }^{\mathrm{C}}$ Key to F-SSCP PCR conditions ( ${ }^{\circ} \mathrm{C}$ annealing temperature, $\mathrm{mM} \mathrm{MgCl}_{2}$ concentration): a - 58, 2; b - 58, 2.5; c - 54, 2.5; d - 58, 4; e - 54, 2; f - 62, 2. 
fragment was amplified from an unaffected control individual and purified by use of the QIAquick PCR purification kit (QIAGEN, Surrey, UK). $1.5 \mu \mathrm{l}$ of each fragment were concentrated by incubation of open tubes at $55^{\circ} \mathrm{C}$ for $10 \mathrm{~min}$. These were denatured by incubation at $95^{\circ} \mathrm{C}$ for $3 \mathrm{~min}$ in the presence of $2-3 \mu$ l loading dye (80\% deionised formamide, $33 \mathrm{~mm} \mathrm{NaOH}, 10 \mathrm{~mm}$ EDTA and $10 \mathrm{mg} / \mathrm{ml}$ blue dextran), followed by chilling on ice. $0.5 \mu$ l of a ROX- or TAMRAlabelled custom size standard, details of which are given below, was added to each sample before loading to enable subsequent lane alignment. Each different fragment was loaded in a separate well and run under both conditions detailed below, to determine their relative electrophoretic mobilities.

Amplified DNA fragments from each proband were then pooled in combinations that allowed peaks corresponding to each amplicon to be distinguished from each other (available on request). These pools, containing up to six different amplicons, were then purified and prepared for loading as above. On each gel, one denatured and one native wild-type control pool were loaded, to respectively eliminate dsDNA peaks and run-to-run variations from the F-SSCP results.

\section{Synthesis of F-SSCP size standard}

The size standard was created by PCR amplifying from genomic DNA using one ROX - or TAMRA-labelled primer and one non-labelled primer. Using a combination of different primers, 14 singly-labelled PCR products with lengths ranging from $146-953 \mathrm{bp}$ were generated. These fragments were purified as above and pooled such that the fluorescent peak intensities generated were approximately equal. The primers were designed from a region of the pterin-4a al pha-carbinolamine dehydratase gene (PCBD, accession no. L41560) and are as follows (5'-3' sequence):

(1) GCTAGT GAC TCC CTC CTG TTC;

(2) TCG AAC AAG TAG CAG TGT CCA;

(3) AAG CAG CCA GTG GAA GCTAA;

(4) TTC ACC CTG TAT CAC AGC TTC;

(5) AGC CTT CAG AAT GTG TCA GAG;

(6) CAC ATC ACG CTG AGC ACC CAT;

(7) CTG GAA GGC CGTGAT GCC ATC TTC;

(8) GCA GGC TGG CAAAGC ACA CAG GCTGA;

(9) GCTACT TGTTCG ATG AAG CTG GC;

(10) CTG GAC TCC CAG TTC AGT CA;

(11) AAATTA GTG TAA CAG AGC CC;

(12) TIT GTAAGG TGA CCC CATCAG;

(13) GGTCTAAATTCC TGG TGTTG;

(14) TTC ACC CTG GAT CAC AGC TTC;

(15) АСТССТ СТАТААТСАТТТ ССС C;

(16) TGTGGACCTTGTTGTACACGT;

(17) AGC CTTCAG AATGTG TCA GAG.

Primers 1-5 only were fluorescently labelled; primer combinations used were as follows (forward primer first): $1 \& 9$;
$1 \& 10 ; 2 \& 11 ; 3 \& 12 ; 1 \& 13 ; 1 \& 11 ; 2 \& 14 ; 6 \& 4 ; 1 \& 14 ; 3 \& 15 ;$ $7 \& 5 ; 8 \& 5 ; 3 \& 16 ; 3 \& 17$. Fragments were PCR amplified with the following cycling conditions: $94^{\circ} \mathrm{C}$ for $15 \mathrm{~min}$; 30 cycles of $94^{\circ} \mathrm{C}$ for $1 \mathrm{~min}, 60^{\circ} \mathrm{C}$ for $1 \mathrm{~min}, 72^{\circ} \mathrm{C}$ for $3 \mathrm{~min} ; 72^{\circ} \mathrm{C}$ for $10 \mathrm{~min}$. The TAMRA-labelled size standard was used with EXT1 fragment pools, while the ROX-labelled version was used for EXT2 pool lane alignment.

\section{F-SSCP running conditions}

Samples were loaded on a $6.5 \%$ 37.5:1 acrylamide gel containing $1 \times$ TBE buffer and 5\% (w/v) glycerol. Electrophoresi s was performed on an ABI PRISM 377 DNA Sequencer (PE-Applied Biosystems) with an attached NESLAB RTE-101 water bath (NESLAB I nstruments Inc., New Hampshire, USA) to maintain accurate temperature control during electrophoresis. Runs were carried out for $8 \mathrm{~h}$ at $60 \mathrm{~W}, 60 \mathrm{~mA}, 4000 \mathrm{~V}$ at $18^{\circ} \mathrm{C}$ in $1 \times$ TBE buffer. Duplicate runs were performed at $25^{\circ} \mathrm{C}$ with gels containing $10 \%$ glycerol. Gel lanes were aligned and analysed using the GeneScan Fragment Analysis program (PE-Applied Biosystems).

\section{DHPLC analysis}

DHPLC analysis was carried out using the WAVE ${ }^{\mathrm{TM}}$ DNA Fragment Analysis System (Transgenomic, Cheshire, UK). Crude PCR products, which had been subjected to denaturation at $95^{\circ} \mathrm{C}$ for $4 \mathrm{~min}$, followed by gradual reannealing from $95^{\circ} \mathrm{C}$ to $25^{\circ} \mathrm{C}$ over $35 \mathrm{~min}$, were injected into a DNASep ${ }^{\mathrm{R}}$ column. The column mobile phase consisted of a linear acetonitrile gradient in a $0.1 \mathrm{~m}$ triethylamine acetate buffer (TEAA), achieved by mixing of buffers $A(0.1 \mathrm{M}$ TEAA), and $B$ ( $25 \%$ acetonitrile in $0.1 \mathrm{~m}$ TEAA). The cal culated gradient at a flow rate of $0.9 \mathrm{ml} / \mathrm{min}$ was run for all the amplicons at the relevant column temperature(s) for each fragment (details on request).

\section{DHPLC gradient and temperature optimisation}

For each different amplicon, the wild-type control was initially applied and subjected to a 16 min universal gradient from $40 \%$ to $72 \%$ buffer $B$ at $50^{\circ} \mathrm{C}$. From this, a $5 \mathrm{~min}$ gradient containing the elution peak was selected to be used in subsequent runs. The column temperature required for optimal resolution of heteroduplexes was determined empirically for each different amplicon by injection of the control DNA at increasing temperatures until a significant decrease in sample retention time was observed. In addition, the EXT2 fragment sequences were entered into the WAVEM aker ${ }^{\mathrm{TM}}$ program (Transgenomic) which derives the optimal column temperature(s) and gradient for each fragment.

\section{Sequencing analysis}

Fragments that showed a variant F-SSCP or DHPLC pattern were further analysed by sequencing. Fragments of interest were PCR amplified from genomic DNA with specific primers (Table1) and then purified. They were directly sequenced in both directions by use of the BigDye Terminator Cycle 
Sequencing Ready Reaction kit (PE-Applied Biosystems) and were run on the $A B I 377$ DNA Sequencer (PE-Applied Biosystems). Where available, amplicons from one affected and one unaffected member of the family were also sequenced, to check that the mutation was found only in the disease phenotype.

\section{Results}

Genomic DNA from 34 unrelated patients with HME was analysed for mutations in the EXT1 and EXT2 genes. DNA fragments covering every translated exon with flanking intronic splice site sequence were amplified and screened blindly with both DHPLC and F-SSCP techniques. All variants detected by either method were sequenced; and all were found to have sequence changes.

Forty-two different amplicon variants, listed in Table2, were detected by blind screening of the EXT1 and EXT2 genes. These arise from 37 different sequence changes, due to overlapping amplicon design for EXT1 exon 1 and EXT2 exon 2. After the initial screen and sequence analysis of variants, electrophoretic data for the four variants detected

Table 2a Sequence changes in the EXT1 gene detected by F-SSCP and/or DHPLC

\begin{tabular}{|c|c|c|c|c|c|}
\hline \multirow[b]{2}{*}{ Sequence change } & \multirow{2}{*}{$\begin{array}{l}\text { Fragment } \\
\text { no. }\end{array}$} & \multirow{2}{*}{$\begin{array}{l}\text { Distance from } \\
\text { nearest end (bp) }\end{array}$} & \multicolumn{3}{|c|}{ Detected in blind screen } \\
\hline & & & DHPLC & F-SSCP & Reason for missing \\
\hline 37delG & $1.1 \mathrm{a}$ & 70 & yes & yes & \\
\hline 86-88delG & $1.1 a$ & $19-21$ & yes & yes & \\
\hline 86-88 delG & $1.1 b$ & $54-56$ & yes & yes & \\
\hline 238delA & $1.1 b$ & 30 & yes & yes & \\
\hline 238delA & 1.2 & 49 & yes & yes & \\
\hline 242-247delC & $1.1 b$ & $21-26$ & yes & NO & mutation not detectable \\
\hline 242-247delC & 1.2 & $53-58$ & yes & yes & \\
\hline 420ins4 & 1.2 & 47 & yes & yes & \\
\hline 420ins4 & 1.3 & 32 & yes & yes & \\
\hline 460-461delTT & 1.3 & $72-73$ & yes & yes & \\
\hline T482G & 1.3 & 94 & yes & NO & human error \\
\hline 713delC & 1.4 & 111 & yes & yes & \\
\hline $962+2 \mathrm{~T}>\mathrm{C}$ & 1.5 & 39 & yes & yes & \\
\hline C1018T & 2 & 100 & yes & yes & \\
\hline G1019T & 2 & 99 & yes & yes & \\
\hline G1019A & 2 & 99 & yes & yes & \\
\hline G1066A & 3 & 45 & yes & yes & \\
\hline A1213T & 4 & 110 & yes & yes & \\
\hline $1284+64 \mathrm{G}>A$ & 4 & 26 & yes & NO & mutation not obvious \\
\hline $1285-2 A>C$ & 5 & 70 & NO & yes & mutation not obvious \\
\hline 1384delC & 5 & 76 & yes & yes & \\
\hline $1418-2 A>G$ & 6 & 42 & yes & yes & \\
\hline C1431T & 6 & 57 & yes & yes & \\
\hline 1463-1468delC & 6 & 89-94 & NO & yes & human error \\
\hline $1536+1 \mathrm{G}>\mathrm{T}$ & 6 & 69 & yes & yes & \\
\hline 1633 -2delA & 8 & 82 & yes & yes & \\
\hline G1761A & 9 & 78 & NO & yes & human error \\
\hline A1807T & 9 & 124 & yes & yes & \\
\hline 1904-1906delC & 10 & $61-63$ & NO & yes & mutation not obvious \\
\hline
\end{tabular}

Table $\mathbf{2 b}$ Sequence changes in the EXT2 gene detected by F-SSCP and/or DHPLC

\begin{tabular}{|c|c|c|c|c|c|}
\hline \multirow[b]{2}{*}{ Sequence change } & \multirow{2}{*}{$\begin{array}{l}\text { Fragment } \\
\text { no. }\end{array}$} & \multirow{2}{*}{$\begin{array}{l}\text { Distance from } \\
\text { nearest end (bp) }\end{array}$} & \multicolumn{3}{|c|}{ Detected in blind screen } \\
\hline & & & DHPLC & F-SSCP & Reason for missing \\
\hline C28A & 2.1 & 111 & yes & yes & \\
\hline G151T & 2.2 & 104 & yes & yes & \\
\hline 450 del4 & 2.3 & 22 & yes & yes & \\
\hline 450 del4 & 2.4 & 101 & yes & yes & \\
\hline G519C & 2.4 & 59 & yes & yes & \\
\hline A520C & 2.4 & 58 & yes & yes & \\
\hline $536+1 \mathrm{G}>A$ & 2.4 & 41 & yes & yes & \\
\hline C544T & 3 & 67 & yes & yes & \\
\hline G679A & 4 & 111 & yes & yes & \\
\hline $1080-18 \mathrm{~T}>\mathrm{A}$ & 7 & 29 & yes & yes & \\
\hline $1173+1 \mathrm{G}>A$ & 7 & 60 & yes & yes & \\
\hline $1174-18 \mathrm{G}>\mathrm{T}$ & 8 & 24 & yes & NO & mutation not detectable \\
\hline
\end{tabular}


by DHPLC but not by F-SSCP technology were re-examined. One of the sequence variants, T482G (Figure1), did actually show a clear electrophoretic mobility shift relative to control DNA. This shift had initially been disregarded, as it had not been anticipated that this class of peak shift could be caused by a genuine heterozygous sequence alteration. This change was in fact detected when analysed using the Genotyper program (PE-Applied Biosystems). Of the amplicons containing the remaining three variants, one was seen to show a change in electrophoretic mobility that was too subtle to be reliably detected by eye, whilst the other two showed no detectable electrophoretic change.

This procedure was repeated for the four sequence changes detected using F-SSCP but not by the DHPLC technique. Two of these were found to have been missed solely due to human
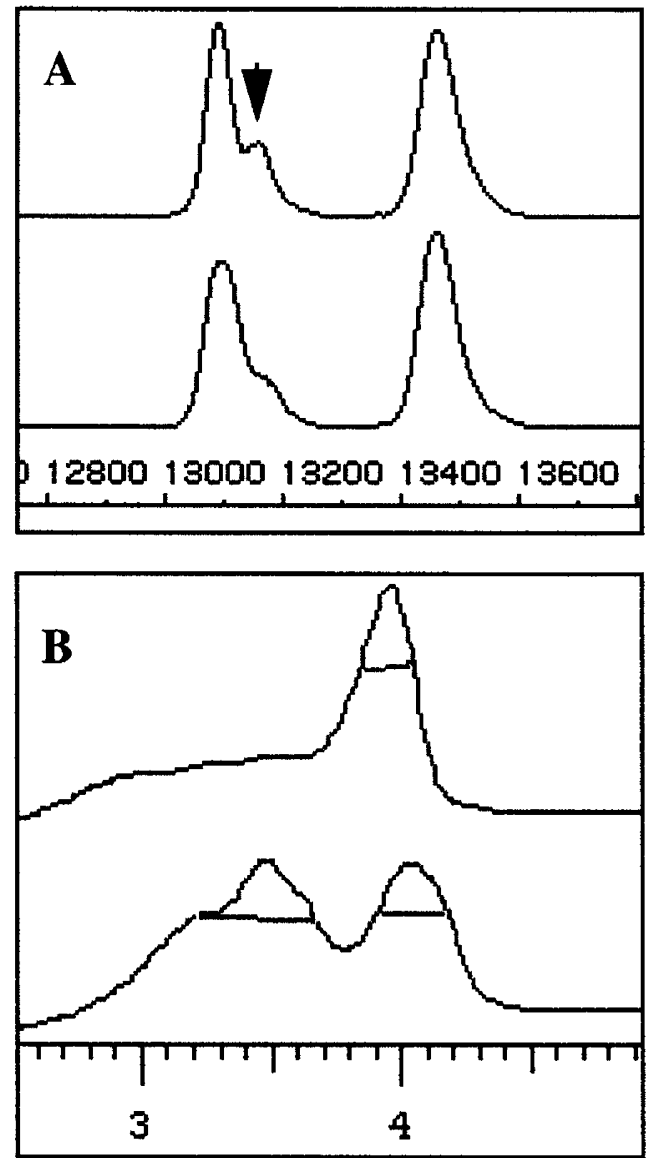

Figure 1 A Comparison of F-SSCP electropherograms for wild-type sequence (top) and the T482G mutation (bottom) in EXT1 exon 1 fragment 3, aligned and analysed using the Genescan Fragment Analysis program. The $x$ axis represents time, the $y$ axis is a measure of fluorescence. Notice that the minor peak on the top trace (arrowed) is lost on the bottom electropherogram, and that the leftmost peak is reduced in height relative to the right-hand peak. B Comparison of the DHPLC elution peaks for the same fragments, analysed using the D/7000 HSM program on the WAVE ${ }^{\mathrm{TM}}$ DNA Fragment Analysis System. error: in the absence of the WAVEMaker ${ }^{\mathrm{TM}}$ temperature prediction facility when analysing EXT1 fragments, the incorrect temperature for resolution had been chosen. The other two variants were deemed to have peak changes too subtle to be reliably detected using the current scoring method.

The detection efficiency rate, assuming that all amplicon variants had been found between the two techniques and discounting human error, was calculated to be $39 / 42=93 \%$ for F-SSCP and 40/42 = 95\% for DHPLC.

Careful examination of the F-SSCP electropherogram data clearly indicates that the genotype of a fragment can be determined for a known polymorphism, as shown in Figure2. Furthermore, when fragments containing a common polymorphism were analysed, additional mutations were clearly distinguishable. In the case of DHPLC, we were unable to differentiate between the two homozygous states for a polymorphism; and heterozygotes for new mutations could not be reliably distinguished from heterozygotes at the polymorphic site.

The 37 different sequence alterations found in EXT1 and EXT2 were subdivided as follows: three were found in intronic sequence, distant from the splice site; five were silent mutations; and two were conservative mutations. The remaining 27 changes, 21 in EXT1 and six in EXT2, were presumed to be the disease mutation in the respective proband, either because the same mutation had been previously reported to be associated with the HME phenotype, or because the mutation was both deduced to result in an aberrant protein and was not found in an unaffected family member. Of these 27 mutations, 16 in EXT1 and three in EXT2 had not been previously reported: these are detailed in Table3. Six of these were splice-site mutations, eight were insertions or deletions leading to a shift in the reading frame which introduced a premature stop codon, and five were nonsense mutations resulting in the synthesis of a truncated product. No previously unreported missense mutations were found.

\section{Discussion \\ HME mutations}

From 34 probands screened, we found 27 different mutations likely to cause HME in 29 families. Nineteen of these disease mutations have not previously been reported, indicating a strong allelic heterogeneity with no one mutation causing the majority of HME cases in the population. 23/27 (85\%) of the mutations detected in this study were loss-of-function mutations, further supporting the theory that EXT1 and EXT2 function as tumour suppressor genes. All missense mutations detected in this study had been previously reported, ${ }^{21,24,25}$ implying that the two amino acid residues involved, R340 in EXT1 and D227 in EXT2, are essential for maintaining correct protein function or stability. 


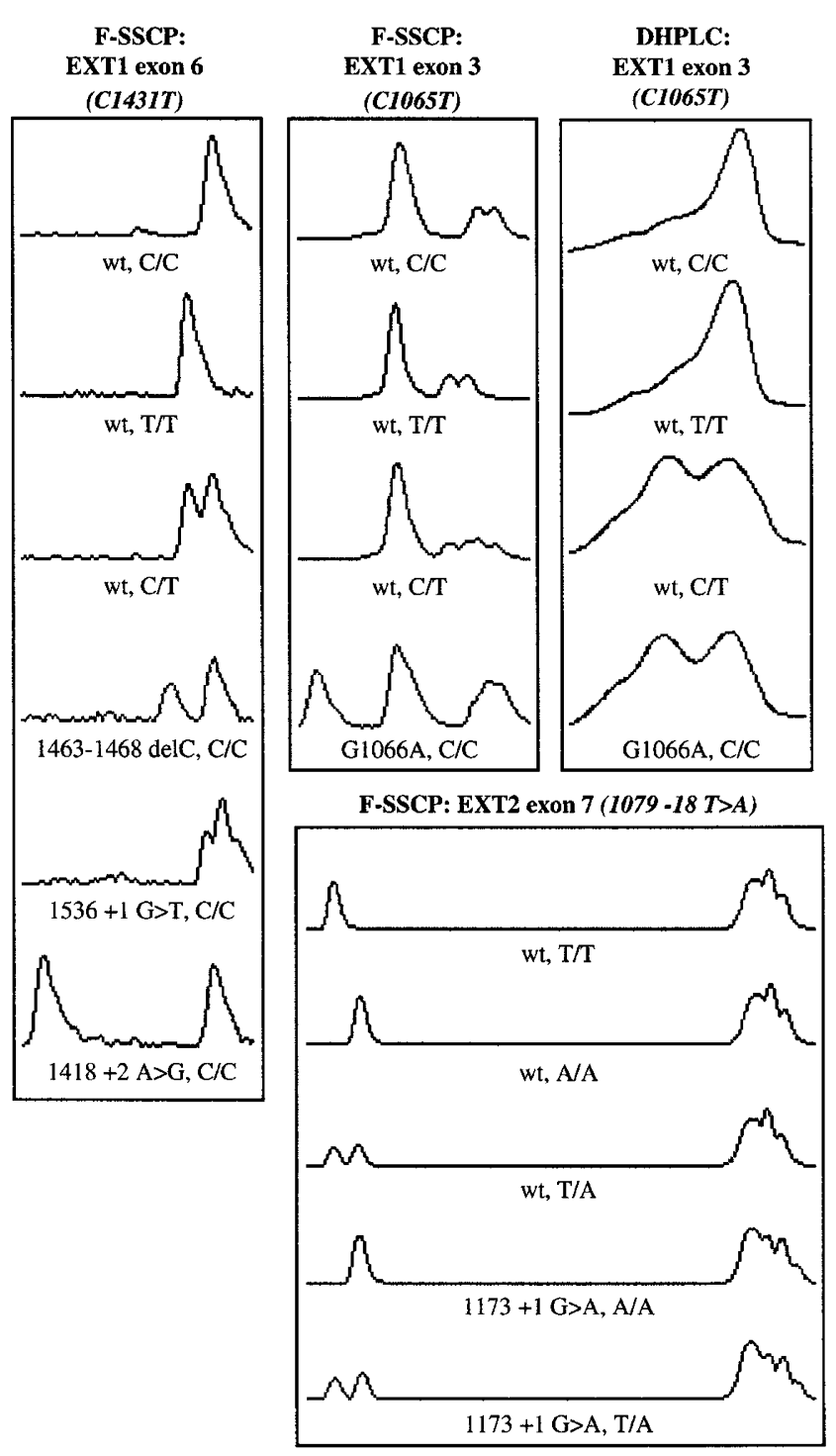

Figure 2 Detection of mutations against a polymorphic background. F-SSCP electropherograms were aligned using the Genescan Fragment Analysis program; DHPLC elution peaks were analysed with the D/7000 HSM program. The detection technique and polymorphism are denoted above the relevant exon group. Each electropherogram is labelled with the disease mutation it represents, followed by the genotype of the polymorphism present. Those electropherograms of fragments with no disease mutation are labelled ' $w t$ '.

Of the 29 families in which mutations were detected, 22 (76\%) had a mutation in the EXT1 gene and seven (24\%) in EXT2. This contrasts with reported proportional EXT1/EXT2 frequencies of $58 \% / 42 \%$ and $50 \% / 50 \%$ in similar studies conducted by Philippe et $\mathrm{al}^{21}$ and Wuyts et $\mathrm{al}^{22}$ respectively, although this is probably an effect of the relatively small number of families screened in all three studies. In five families in this study (15\%), no mutations in either EXT1 or
EXT2 were detected. This could be due to several factors: the limitations of the mutation screening techniques used; the fact that $5^{\prime}$ and $3^{\prime}$ UTRs and promoter regions of the two genes were not analysed; or the existence of other HMEcausing genes. The two studies by Philippe et al and Wuyts et al reported respectively that $29 \%$ and $23 \%$ of families with the HME phenotype had no detectable EXT1 or EXT2 mutations. $^{21,22}$ The discrepancy between these figures and ours could be ascribed to the decreased sensitivities of conformation-sensitive gel electrophoresis and conventional SSCP - the respective mutation detection techniques employed by those studies - when compared with our combined F-SSCP and DHPLC strategy.

\section{Comparison of DHPLC and F-SSCP}

The mutation detection rates for DHPLC and F-SSCP, as determined in this study, are very similar: $95 \%$ and $93 \%$ respectively. These figures are not absolute, as it is not possible to rule out the occurrence of sequence variants that have passed undetected by either technique without sequencing all 1088 fragments in both directions. It is reasonable, however, to conclude that both methods are capable of high sensitivities. Looking in detail at the base changes undetected by F-SSCP, it can be seen that they are all positioned $<30 \mathrm{bp}$ from the amplicon ends. This is in contrast to results from work with conventional SSCP, where position of base change has been reported to play little role in sensitivity. ${ }^{26-28}$ It follows that judicious design of primers sufficiently far from the region of interest will further increase mutation detection using this technique. Looking at the changes deemed undetectable by DHPLC reveals no such obvious trend: a larger study would be necessary for drawing any conclusions about the nature of 'missed' variants. This study has only assayed the detection efficiency for fragments within the optimal size range recommended for SSCP, ie 150-300 bp. ${ }^{29}$ It is known that conventional SSCP sensitivity drops sharply for fragments larger than $300 \mathrm{bp.}^{29,30}$ This is in contrast to DHPLC, where single base mutations have been detected in fragments as large as $1.5 \mathrm{~kb},{ }^{31}$ although manufacturers of the integrated system recommend that for optimal sensitivity, amplicons should be kept to a maximum of $450 \mathrm{bp}^{4}$

Also of interest when considering screening strategies is the ability of a particular technique to determine the genotype of a single nucleotide polymorphism (SNP). As shown in Figure2, it is possible to distinguish between all three genotypes for the common SNPs encountered in this study when using F-SSCP. In contrast, the two homozygous states for the SNPS cannot be differentiated from each other using the DHPLC protocol detailed here. This could be simply achieved by comparison of the data with that gleaned from prior mixing of the fragments with a homozygous reference sample, although this would increase running and analysis time. A related concern is whether a technique is capable of distinguishing between different mutations in the same 
fragment. For example, EXT1 exon 3 contains a C/T polymorphism at position 1065 (cDNA numbering). One individual in our study was homozygous for this polymorphism, but was heterozygous for the G1066A mutation immediately adjacent. As shown in Figure2, these two sequence variants can be clearly distinguished by F-SSCP: this is not the case with DHPLC. This may have implications for the utility of the latter technique in mutation screening if there is a relatively common polymorphism in the region of interest.

Sensitivity of detection is not the only factor that must be taken into account when evaluating techniques that identify sequence variants. Throughput, ease of application and cost are all elements that must be considered in the choice of a screening technique.

Throughput In this study, 185-222 amplicons were routinely screened in one $8 \mathrm{~h}$ F-SSCP electrophoresis. It is envisaged that multiplexing 9 fragments in one lane will be practically viable, enabling the running of up to 576 fragments in a single el ectrophoresis when using a 64-well gel. With present technology, it was possible to screen only 49 amplicons in $8 \mathrm{~h}$ using DHPLC. However, equipment is available that allows faster column cleaning and equilibration between injections, which could substantially increase throughput.

Ease of application Both F-SSCP and DHPLC are relatively simple techniques, involving standard processes. PCR amplification is perhaps easier with F-SSCP because a standard Taq polymerase is sufficient for the reaction. This is not the case with DHPLC: this technique is susceptible to errors introduced in PCR and therefore requires the presence of a proofreading polymerase. Unfortunately, these polymerases are more sensitive to DNA quality, which resulted in repeat amplifications being required for some samples in this study. However, once DNA fragments have been amplified, DHPLC is far quicker to set up, as it includes no time-consuming purification or gel-pouring steps.

Cost The protocol for DHPLC employed in this study is calculated to be $£ 0.79$ per amplicon, assuming the process is run at only one temperature. (An additional temperature is often required, depending on the melting profile of the DNA fragment: this costs an extra $£ 0.33$ per amplicon). The F-SSCP protocol used here is calculated to cost $£ 0.61$ for one fragment when run under the two electrophoresis conditions. However, this calculation assumes full consumption of thefluorescent primers, which is unlikely to bethe case when screening only a few individuals. This initial cost, which can rise greatly if screening many different exons, can be circumvented by the use of an alternative protocol, post-label F-SSCP. ${ }^{32}$ This technique involves amplification of the DNA region of interest using unlabelled primers with 5 ' ATT extensions, then performing a Klenow fragment nucleotide exchange reaction with fluorescently-labelled dUTPs. This has proved successful in our hands and should theoretically result in no loss of sensitivity, although this has not been thoroughly tested.

In summary, both DHPLC and F-SSCP display very high mutation detection rates in this study. The main strengths of DHPLC are its extreme ease of application and analysis and its relatively low cost. This makes this technology ideal for screening large regions of the genome in relatively few individuals for single nucleotide polymorphisms, or for screening potential candidate genes for mutations associated with the disease in question. The main advantages associated with F-SSCP are its capacity for extremely high through put and its ability to distinguish between different mutations in the same fragment. It is therefore ideally suited for screening a large number of individuals for mutations in a known disease gene that has relatively few exons. With this in mind,

Table 3 Previously unreported mutations identified in the EXT1 and EXT2 genes

\begin{tabular}{|c|c|c|c|c|}
\hline cDNA change & Gene & Exon or intron & Protein change & Type of mutation \\
\hline 37delG & EXT1 & Exon 1 & FS & Frameshift \\
\hline 86-88delG & EXT1 & Exon 1 & FS & Frameshift \\
\hline 238delA & EXT1 & Exon 1 & FS & Frameshift \\
\hline 242-247delC & EXT1 & Exon 1 & FS & Frameshift \\
\hline 460-461delTT & EXT1 & Exon 1 & FS & Frameshift \\
\hline $\mathrm{T} 482 \mathrm{G}$ & EXT1 & Exon 1 & L161X & Nonsense \\
\hline $962+2 T>C$ & EXT1 & Intron 1 & $?$ & Splice site \\
\hline $\mathrm{A} 1213 \mathrm{~T}$ & EXT1 & Exon 4 & R405X & Nonsense \\
\hline $1285-2 A>C$ & EXT1 & Intron 4 & ? & Splice site \\
\hline 1384delC & EXT1 & Exon 5 & FS & Frameshift \\
\hline $1418-2 A>G$ & EXT1 & Intron 5 & $?$ & Splice site \\
\hline 1463-1468delC & EXT1 & Exon 6 & FS & Frameshift \\
\hline $1536+1 \mathrm{G}>\mathrm{T}$ & EXT1 & Intron 6 & $?$ & Splice site \\
\hline 1633 -2delA & EXT1 & Intron 7 & $?$ & Splice site \\
\hline A1807T & EXT1 & Exon 9 & K603X & Nonsense \\
\hline 1904-1906delC & EXT1 & Exon 10 & FS & Frameshift \\
\hline G151T & EXT2 & Exon 2 & E51X & Nonsense \\
\hline C544T & EXT2 & Exon 3 & R181X & Nonsense \\
\hline
\end{tabular}


we have decided to continue with F-SSCP in our screening strategy for mutations in EXT1 and EXT2.

\section{Acknowledgements}

The authors would like to thank the patients and their families, who provided blood and buccal samples for this study; and Christophe Philippe, for initiation of the study. This work was funded by the Arthritis and Rheumatism Council Project Grant number P0540. APM is a Wellcome Trust Principal Research Fellow.

\section{References}

1 Orita M, I wahana H, Kanazawa H, Hayashi K, Sekiya T: Detection of polymorphisms of human DNA by gel electrophoresis as singlestrand conformation polymorphisms. Proc Natl Acad Sci USA 1989; 86: $2766-2770$

2 Oefner PJ, Underhill PA: Comparative DNA sequencing by denaturing high-performance liquid chromatography (DHPLC). Am J Hum Genet 1995; 57(Suppl): A266.

3 Iwahana H, Yoshimoto K, Mizusawa N, Kudo E, Itakura M: Multiple fluorescence-based PCR-SSCP analysis. Biotechniques 1994; 16: 296-297, 300-295.

4 Kuklin A, Munson K, Gjerde D, Haefele R, Taylor P: Detection of single-nucleotide polymorphisms with the WAVE ${ }^{\mathrm{TM}}$ DNA Fragment Analysis System. Genetic Testing 1997; 1: 201-206.

5 Solomon L: Hereditary multiple exostosis. J Bone Joint Surg 1963; 45B: 292-304.

6 Solomon L: Hereditary multiple exostosis. Am J Hum Genet 1964; 16: 351-363.

7 Hennekam RC: Hereditary multiple exostoses. J Med Genet 1991; 28: 262-266.

8 Schmale GA, Conrad EU, Raskind WH: The natural history of hereditary multiple exostoses. J Bone Joint Surg 1994; 76: 986-992.

9 Cook A, Raskind W, Blanton SH et al: Genetic heterogeneity in families with hereditary multiple exostoses. Am J Hum Genet 1993; 53: 71-79.

10 Wu YQ, Heutink P, de Vries BB et al: Assignment of a second locus for multiple exostoses to the pericentromeric region of chromosome 11. Hum Mol Genet 1994; 3: 167-171.

11 Wuyts W, Ramlakhan S, Van Hul W et al: Refinement of the multiple exostoses locus (EXT2) to a 3-CM interval on chromosome 11. Am J Hum Genet 1995; 57: 382-387.

12 Le Merrer $M$, Legeai Mallet $L$, Jeannin PM et al: A gene for hereditary multiple exostoses maps to chromosome 19p. Hum Mol Genet 1994; 3: 717-722.

13 Ahn J, Ludecke HJ, Lindow Set al: Cloning of the putative tumour suppressor gene for hereditary multiple exostoses (EXT1). Nat Genet 1995; 11: 137-143.

14 Stickens D, Clines G, Burbee D et al: The EXT2 multiple exostoses gene defines a family of putative tumour suppressor genes. Nat Genet 1996; 14: 25-32.

15 Wuyts W, Van Hul W, Wauters J et al: Positional cloning of a gene involved in hereditary multiple exostoses. Hum Mol Genet 1996; 5: 1547-1557.

16 Hecht JT, Hogue D, Strong LC, Hansen MF, Blanton SH, Wagner M: Hereditary multiple exostosis and chondrosarcoma: linkage to chromosome 11 and loss of heterozygosity for EXT-linked markers on chromosomes 11 and 8. Am J Hum Genet 1995; 56: 1125-1131.
17 Raskind WH, Conrad EU, Chansky H, Matsushita M: Loss of heterozygosity in chondrosarcomas for markers linked to hereditary multiple exostoses loci on chromosomes 8 and 11 . Am J Hum Genet 1995; 56: 1132-1139.

18 McCormick C, Leduc Y, Martindale D et al: The putative tumour suppressor EXT1 alters the expression of cell-surface heparan sulfate. Nat Genet 1998; 19: 158-161.

19 Lind T, Tufaro F, McCormick C, Lindahl U, Lidholt K: The putative tumor suppressors EXT1 and EXT2 are glycosyltransferases required for the biosynthesis of heparan sulfate. J Biol Chem 1998; 273: 26265-26268.

20 Bernstein LR, Liotta LA: M olecular mediators of interactions with extracellular matrix components in metastasis and angiogenesis. Curr Opin Oncol 1994; 6: 106-113.

21 Philippe C, Porter DE, Emerton ME, Wells DE, Simpson AH, Monaco AP: Mutation screening of the EXT1 and EXT2 genes in patients with hereditary multiple exostoses. Am J Hum Genet 1997; 61: $520-528$.

22 Wuyts W, Van Hul W, De Boulle K et al: Mutations in the EXT1 and EXT2 genes in hereditary multiple exostoses. Am J Hum Genet 1998; 62: 346-354.

23 Wells DE, Hill A, Lin X, Ahn J, Brown N, Wagner MJ: Identification of novel mutations in the human EXT1 tumor suppressor gene. Hum Genet 1997; 99: 612-615.

24 Raskind WH, Conrad EU, Matsushita M et al: Evaluation of locus heterogeneity and EXT1 mutations in 34 families with hereditary multiple exostoses. Hum Mutat 1998; 11: 231-239.

25 Hecht JT, Hogue D, Wang $Y$ et al: Hereditary multiple exostoses (EXT): mutational studies of familial EXT1 cases and EXTassociated malignancies. Am J Hum Genet 1997; 60: 80-86.

26 Markoff A, Savov A, Vladimirov V, Bogdanova N, Kremensky I, Ganev V: Optimization of single-strand conformation polymorphism analysis in the presence of polyethylene glycol. Clin Chem 1997; 43: 30-33.

27 Markoff $A$, Sormbroen $H$, Bogdanova $N$ et al: Comparison of conformation-sensitive gel electrophoresis and single-strand conformation polymorphism analysis for detection of mutations in the BRCAl gene using optimized conformation analysis protocols. Eur J Hum Genet 1998; 6: 145-150.

28 Glavac D, Dean M: Optimization of the single-strand conformation polymorphism (SSCP) technique for detection of point mutations. Hum Mutat 1993; 2: 404-414.

29 Hayashi K: PCR-SSCP: a simple and sensitive method for detection of mutations in the genomic DNA. PCR Methods Appl 1991; 1: 34-38.

30 Sheffield VC, Beck JS, Kwitek AE, Sandstrom DW, Stone EM: The sensitivity of single-strand conformation polymorphism analysis for the detection of single base substitutions. Genomics 1993; 16: 325-332.

31 O'Donovan MC, Oefner PJ, Roberts SC et al: Blind analysis of denaturing high-performance liquid chromatography as a tool for mutation detection. Genomics 1998; 52: 44-49.

32 Inazuka M, Wenz HM, Sakabe M, Tahira T, Hayashi K: A streamlined mutation detection system: multicolor post-PCR fluorescence labeling and single-strand conformational polymorphism analysis by capillary electrophoresis. Genome Res 1997; 7: 1094-1103. 